\title{
On Fixed Points of $\alpha-\psi$-Contractive Multivalued Mappings in Cone Metric Spaces
}

\author{
Marwan Amin Kutbi, ${ }^{1}$ Jamshaid Ahmad, ${ }^{2}$ and Akbar Azam ${ }^{2}$ \\ ${ }^{1}$ Department of Mathematics, King Abdul Aziz University, P.O. Box 80203, Jeddah 21589, Saudi Arabia \\ ${ }^{2}$ Department of Mathematics, COMSATS Institute of Information Technology, Chak Shahzad, Islamabad 44000, Pakistan
}

Correspondence should be addressed to Akbar Azam; akbarazam@yahoo.com

Received 10 July 2013; Revised 13 September 2013; Accepted 19 September 2013

Academic Editor: Salvador Romaguera

Copyright (C) 2013 Marwan Amin Kutbi et al. This is an open access article distributed under the Creative Commons Attribution License, which permits unrestricted use, distribution, and reproduction in any medium, provided the original work is properly cited.

We define the notion of $\alpha^{*}-\psi$-contractive mappings for cone metric space and obtain fixed points of multivalued mappings in connection with Hausdorff distance function for closed bounded subsets of cone metric spaces. We obtain some recent results of the literature as corollaries of our main theorem. Moreover, a nontrivial example of $\alpha^{*}-\psi$-contractive mapping satisfying all conditions of our main result has been constructed.

\section{Introduction}

Banach contraction principle is widely recognized as the source of metric fixed point theory. Also, this principle plays an important role in several branches of mathematics. For instance, it has been used to study the existence of solutions for nonlinear equations, systems of linear equations, and linear integral equations and to prove the convergence of algorithms in computational mathematics. Because of its importance for mathematical theory, Banach contraction principle has been extended in many directions.

In 2007, Huang and zhang [1] introduced cone metric space with normal cone, as a generalization of metric space. Rezapour and Hamlbarani [2] presented the results of [1] for the case of cone metric space without normality in cone. Many authors work out on it (see [3, 4]). Cho and Bae [5] introduced the Hausdorff distance function on cone metric spaces and generalized the result of [6] for multivalued mappings.

In 2012, Samet et al. [7] introduced the concept of $\alpha-\psi$ contractive type mappings. Their results generalized some ordered fixed point results (see [7]). In [8], Karapinar et al. introduced the notion of a $G^{m}$-Meir-Keeler contractive mapping and established some fixed point theorems for the $G^{m_{-}}$ Meir-Keeler contractive mapping in the setting of G-metric spaces. For more details in fixed point theory related to our paper, we refer to the reader [9-19]. Asl et al. [20] introduced the notion of $\alpha^{*}-\psi$-contractive mappings and improved the concept of $\alpha-\psi$-contractive mappings along with some fixed point theorems in metric space. Consequently, Ali et al. [21], Mohammadi et al. [22] and Salimi et al. [23] studied the concept of $\alpha^{*}-\psi$-contractive mappings for proving fixed point results by using generalized contractive conditions in complete metric spaces.

In this paper, we first define the notion of $\alpha^{*}-\psi$ contractive mappings for cone metric spaces and then we use it to study fixed point theorems for multivalued mappings satisfying $\alpha^{*}-\psi$-contractive conditions in a complete cone metric space without the assumption of normality. We also furnish a nontrivial example to support our main result.

\section{Preliminaries}

In the following, we always suppose that $\mathbb{E}$ is a real Banach space, $P$ is a cone in $\mathbb{E}$ with nonempty interior, and $\preceq$ is the partial ordering with respect to $P$. By $\theta$, we denote the zero element of $\mathbb{E}$. A subset $P$ is called a cone if and only if

(i) $P$ is closed, nonempty, and $P=\{\theta\}$;

(ii) $a, b \in \mathbb{R}, a, b \geq 0, x, y \in P \Rightarrow a x+b y \in P$;

(iii) $P \cap(-P)=\{\theta\}$. 
For a given cone $P \subseteq \mathbb{E}$, we define a partial ordering $\preceq$ with respect to $P$ by $x \preceq y$ if and only if $y-x \in P$; $x \prec y$ will stand for $x \preceq y$ and $x \neq y$, while $x \ll y$ stand for $y-x \in$ int $P$, where int $P$ denotes the interior of $P$.

Definition 1 (see [1]). Let $X$ be a nonempty set. A function $d: X \times X \rightarrow \mathbb{E}$ is said to be a cone metric, if the following conditions hold:

(C1) $\theta \preceq d(x, y)$ for all $x, y \in X$ and $d(x, y)=\theta$ if and only if $x=y$;

(C2) $d(x, y)=d(y, x)$ for all $x, y \in X$;

(C3) $d(x, z) \preceq d(x, y)+d(y, z)$ for all $x, y, z \in X$.

The pair $(X, d)$ is then called a cone metric space.

Lemma 2 (see $[1])$. Let $(X, d)$ be a cone metric space, $x \in X$, and let $\left\{x_{n}\right\}$ be a sequence in $X$. Then

(i) $\left\{x_{n}\right\}$ converges to $x$ whenever for everyc $\in \mathbb{E}$ with $\theta \ll c$ there is a natural number $n_{0}$ such that $d\left(x_{n}, x\right) \ll c$, for all $n \geq n_{0}$. We denote this by $\lim _{n \rightarrow \infty} x_{n}=x$;

(ii) $\left\{x_{n}\right\}$ is a Cauchy sequence whenever for every $c \in \mathbb{E}$ with $\theta \ll c$ there is a natural number $n_{0}$ such that $d\left(x_{n}, x_{m}\right) \ll c$, for all $n, m \geq n_{0}$;

(iii) $(X, d)$ is complete cone metric if every Cauchy sequence in $X$ is convergent.

Remark 3 (see [3]). The results concerning fixed points and other results, in case of cone spaces with nonnormal cones, cannot be provided by reducing to metric spaces, because in this case neither of the conditions of the lemmas 1-4, in [1] hold. Further, the vector cone metric is not continuous in the general case; that is, from $x_{n} \rightarrow x, y_{n} \rightarrow y$ it need not follow that $d\left(x_{n}, y_{n}\right) \rightarrow d(x, y)$.

Let $(X, d)$ be a cone metric space. The following properties of cone metric spaces have been noticed [3].

(PT1) If $u \preceq v$ and $v \ll w$, then $u \ll w$.

(PT2) If $u \ll v$ and $v \preceq w$, then $u \ll w$.

(PT3) If $u \ll v$ and $v \ll w$, then $u \ll w$.

(PT4) If $\theta \preceq u \ll c$ for each $c \in \operatorname{int} P$, then $u=\theta$.

(PT5) If $a \preceq b+c$, for each $c \in$ int $P$, then $a \preceq b$.

(PT6) $\left\{a_{n}\right\}$ be a sequence in $\mathbb{E}$. If $c \in$ int $P$ and $\theta \preceq a_{n} \rightarrow \theta$ (as $n \rightarrow \infty$ ), then there exists $n_{0} \in N$ such that for all $n \geq n_{0}$, we have $a_{n} \ll c$.

With some modifications, we have the following definition from [24].

Definition 4. Let $\Psi$ be a family of nondecreasing functions, $\psi: P \rightarrow P$ such that

(i) $\psi(\theta)=\theta$ and $\theta<\psi(t)<t$ for $t \in P \backslash\{\theta\}$,

(ii) $t \in \operatorname{Int} P$ implies $t-\psi(t) \in \operatorname{Int} P$,

(iii) $\lim _{n \rightarrow+\infty} \psi^{n}(t)=\theta$ for every $t \in P \backslash\{\theta\}$.

\section{Main Result}

For a cone metric space $(X, d)$, denote (see [5])

$$
\begin{gathered}
N(X)=\{A: A \text { is non empty subset of } X\} \\
C B(X)=\{A: A \text { is non empty, } \\
\text { closed and bounded subset of } X\}, \\
s(p)=\{q \in \mathbb{E}: p \preceq q\} \quad \text { for } q \in \mathbb{E}, \\
s(a, B)=\bigcup_{b \in B} s(d(a, b))=\bigcup_{b \in B}\{x \in \mathbb{E}: d(a, b) \preceq x\}
\end{gathered}
$$

for $a \in X$ and $B \in C B(X)$.

For $A, B \in C B(X)$ we denote

$$
s(A, B)=\left(\bigcap_{a \in A} s(a, B)\right) \cap\left(\bigcap_{b \in B} s(b, A)\right) .
$$

Lemma 5. Let $(X, d)$ be a cone metric space, and let $P$ be a cone in Banach space $\mathbb{E}$.

(1) Let $p, q \in \mathbb{E}$. If $p \preceq q, s(q) \subset s(p)$.

(2) Let $x \in X$ and $A \in N(X)$. If $\theta \in s(x, A)$, then $x \in A$.

(3) Let $q \in P$ and let $A, B \in C B(X)$ and $a \in A$. If $q \in$ $s(A, B)$, then $q \in s(a, B)$ for all $a \in A$ or $q \in s(A, b)$ for all $b \in B$.

(4) Let $q \in P$ and let $\lambda \geq 0$, then $\lambda s(q) \subseteq s(\lambda q)$.

Remark 6. Let $(X, d)$ be a cone metric space. If $\mathbb{E}=R$ and $P=[0,+\infty)$, then $(X, d)$ is a metric space. Moreover, for $A, B \in C B(X), H(A, B)=\inf s(A, B)$ is the Hausdorff distance induced by $d$.

Definition 7. Let $(X, d)$ be a complete cone metric space with cone $P, \psi \in \Psi, \alpha: X \times X \rightarrow[0,+\infty)$, and $F: X \rightarrow C B(X)$ is known as $\alpha^{*}-\psi$-contractive multivalued mapping whenever

$$
\psi(d(x, y)) \in \alpha^{*}(F x, F y) s(F x, F y)
$$

for all $x, y \in X$, where $\alpha^{*}(A, B)=\inf \{\alpha(a, b): a \in A, b \in B\}$. Also, we say that $F$ is $\alpha^{*}$-admissible whenever $\alpha(x, y) \geq 1$ implies $\alpha^{*}(F x, F y) \geq 1$.

Note that an $\alpha^{*}-\psi$-contractive multivalued mappings for cone metric space is generalized $\alpha^{*}-\psi$-contractive. When $\psi \in$ $\Psi$ is a strictly increasing mapping, $\alpha^{*}-\psi$-contractive is called strictly generalized $\alpha^{*}-\psi$-contractive.

Theorem 8. Let $(X, d)$ be a complete cone metric space with cone $P, \alpha: X \times X \rightarrow[0,+\infty)$ be a function, $\psi \in \Psi$ be a strictly increasing map and $F: X \rightarrow C B(X)$, and $F$ be $\alpha^{*}$-admissible and $\alpha^{*}-\psi$-contractive multivalued mapping on $X$. Suppose that there exist $x_{0} \in X, x_{1} \in F x_{0}$ such that $\alpha\left(x_{0}, x_{1}\right) \geq 1$. Assume that if $\left\{x_{n}\right\}$ is a sequence in $X$ such that $\alpha\left(x_{n}, x_{n+1}\right) \geq 1$ for all $n$ and $x_{n} \rightarrow u$ as $n \rightarrow+\infty$ then $\alpha\left(x_{n}, u\right) \geq 1$ for all $n$. Then, there exists a point $x^{*}$ in $X$ such that $x^{*} \in F x^{*}$. 
Proof. We may suppose that $x_{0} \neq x_{1}$. Then $\alpha^{*}\left(F x_{0}, F x_{1}\right) \geq 1$ and

$$
\psi\left(d\left(x_{0}, x_{1}\right)\right) \in \alpha^{*}\left(F x_{0}, F x_{1}\right) s\left(F x_{0}, F x_{1}\right) .
$$

By Lemma 5(3), we have

$$
\psi\left(d\left(x_{0}, x_{1}\right)\right) \in \alpha^{*}\left(F x_{0}, F x_{1}\right) s\left(x_{1}, F x_{1}\right) .
$$

By definition, we can take $x_{2} \in F x_{1}$ such that

$$
\psi\left(d\left(x_{0}, x_{1}\right)\right) \in \alpha^{*}\left(F x_{0}, F x_{1}\right) s\left(d\left(x_{1}, x_{2}\right)\right) .
$$

By Lemma 5(4), we have

$$
\begin{aligned}
\psi\left(d\left(x_{0}, x_{1}\right)\right) & \in \alpha^{*}\left(F x_{0}, F x_{1}\right) s\left(d\left(x_{1}, x_{2}\right)\right) \\
& \subseteq s\left(\alpha^{*}\left(F x_{0}, F x_{1}\right) d\left(x_{1}, x_{2}\right)\right) .
\end{aligned}
$$

So,

$$
\alpha^{*}\left(F x_{0}, F x_{1}\right) d\left(x_{1}, x_{2}\right) \preceq \psi\left(d\left(x_{0}, x_{1}\right)\right)
$$

Hence,

$$
0 \prec d\left(x_{1}, x_{2}\right) \preceq \alpha^{*}\left(F x_{0}, F x_{1}\right) d\left(x_{1}, x_{2}\right) \preceq \psi\left(d\left(x_{0}, x_{1}\right)\right)
$$

$x_{1} \neq x_{2}$ and $\alpha\left(x_{1}, x_{2}\right) \geq 1$. Thus $\alpha^{*}\left(F x_{1}, F x_{2}\right) \geq 1$ and $d\left(x_{1}, x_{2}\right) \preceq \psi\left(d\left(x_{0}, x_{1}\right)\right)$. If $x_{2} \in F x_{2}$, then $x_{2}$ is a fixed point of $F$. Assume that $x_{2} \notin F x_{2}$. Then

$$
\psi\left(d\left(x_{1}, x_{2}\right)\right) \in \alpha^{*}\left(F x_{1}, F x_{2}\right) s\left(F x_{1}, F x_{2}\right) .
$$

By Lemma 5(3), we have

$$
\psi\left(d\left(x_{1}, x_{2}\right)\right) \in \alpha^{*}\left(F x_{1}, F x_{2}\right) s\left(x_{2}, F x_{2}\right) .
$$

By definition, we can take $x_{3} \in F x_{2}$ such that

$$
\psi\left(d\left(x_{1}, x_{2}\right)\right) \in \alpha^{*}\left(F x_{1}, F x_{2}\right) s\left(d\left(x_{2}, x_{3}\right)\right) .
$$

By Lemma 5(4), we have

$$
\begin{aligned}
\psi\left(d\left(x_{1}, x_{2}\right)\right) & \in \alpha^{*}\left(F x_{1}, F x_{2}\right) s\left(d\left(x_{2}, x_{3}\right)\right) \\
& \subseteq s\left(\alpha^{*}\left(F x_{1}, F x_{2}\right) d\left(x_{2}, x_{3}\right)\right) .
\end{aligned}
$$

So,

$$
\alpha^{*}\left(F x_{1}, F x_{2}\right) d\left(x_{2}, x_{3}\right) \preceq \psi\left(d\left(x_{1}, x_{2}\right)\right) .
$$

Hence,

$$
0 \prec d\left(x_{2}, x_{3}\right) \preceq \alpha^{*}\left(F x_{1}, F x_{2}\right) d\left(x_{2}, x_{3}\right) \preceq \psi\left(d\left(x_{1}, x_{2}\right)\right) .
$$

It is clear that $x_{2} \neq x_{3}$ and $\alpha\left(x_{2}, x_{3}\right) \geq 1$. Thus, $\alpha^{*}\left(F x_{2}, F x_{3}\right) \geq 1$ and $d\left(x_{2}, x_{3}\right)<\psi^{2}\left(\psi\left(d\left(x_{0}, x_{1}\right)\right)\right)$.

If $x_{3} \in F x_{3}$, then $x_{3}$ is a fixed point of $F$. Assume that $x_{3} \notin F x_{3}$ :

$$
\psi\left(d\left(x_{2}, x_{3}\right)\right) \in \alpha^{*}\left(F x_{2}, F x_{3}\right) s\left(F x_{2}, F x_{3}\right) .
$$

By Lemma 5(3), we have

$$
\psi\left(d\left(x_{2}, x_{3}\right)\right) \in \alpha^{*}\left(F x_{2}, F x_{3}\right) s\left(x_{3}, F x_{3}\right) .
$$

By definition, we can take $x_{4} \in F x_{3}$ such that

$$
\psi\left(d\left(x_{2}, x_{3}\right)\right) \in \alpha^{*}\left(F x_{2}, F x_{3}\right) s\left(d\left(x_{3}, x_{4}\right)\right) .
$$

By Lemma 5(4), we have

$$
\begin{aligned}
\psi\left(d\left(x_{2}, x_{3}\right)\right) & \in \alpha^{*}\left(F x_{2}, F x_{3}\right) s\left(d\left(x_{3}, x_{4}\right)\right) \\
& \subseteq s\left(\alpha^{*}\left(F x_{2}, F x_{3}\right) d\left(x_{3}, x_{4}\right)\right) .
\end{aligned}
$$

So

$$
\alpha^{*}\left(F x_{2}, F x_{3}\right) d\left(x_{3}, x_{4}\right) \preceq \psi\left(d\left(x_{2}, x_{3}\right)\right)
$$

Hence

$$
0 \prec d\left(x_{3}, x_{4}\right) \preceq \alpha^{*}\left(F x_{2}, F x_{3}\right) d\left(x_{3}, x_{4}\right) \preceq \psi\left(d\left(x_{2}, x_{3}\right)\right) .
$$

It is clear that $x_{3} \neq x_{4}$ and $\alpha\left(x_{3}, x_{4}\right) \geq 1$. Thus, $\alpha^{*}\left(F x_{3}, F x_{4}\right) \geq 1$ and $d\left(x_{3}, x_{4}\right)<\psi^{3}\left(\psi\left(d\left(x_{0}, x_{1}\right)\right)\right)$. By continuing this process, we obtain a sequence $\left\{x_{n}\right\}$ in $X$ such that $x_{n} \in T x_{n-1}, x_{n} \neq x_{n-1}, \alpha\left(x_{n}, x_{n+1}\right) \geq 1$ and

$$
d\left(x_{n}, x_{n+1}\right) \preceq \psi\left(d\left(x_{n-1}, x_{n}\right)\right) \preceq \cdots \preceq \psi^{n}\left(d\left(x_{0}, x_{1}\right)\right)
$$

for all $n$.

Fix $\theta \ll c$. We choose a positive real number $\delta$ such that $(c-\psi(c))+I(\theta, \delta) \subset \operatorname{Int} P$, where $I(\theta, \delta)=\{y \in E:\|y\|<\delta\}$. By (iii) of Definition 4 , there exists a natural number $N$ such that $\psi^{m}\left(d\left(x_{0}, x_{1}\right)\right) \in I(\theta, \delta)$, for all $m \geq N$. Then

$$
\psi^{m}\left(d\left(x_{0}, x_{1}\right)\right) \ll c-\psi(c),
$$

for all $m \geq N$. Consequently, $d\left(x_{m}, x_{m+1}\right) \ll c-\psi(c)$, for all $m \geq N$. Fix $m \geq N$. Now we prove

$$
d\left(x_{m}, x_{n+1}\right) \ll c
$$

for all $n \geq m$. Note that (24) holds when $n=m$. Assume that (24) holds for some $n \geq m$. Then, we have

$$
d\left(x_{m}, x_{n+1}\right) \ll c .
$$

Now by (22), we have

$$
\begin{aligned}
d\left(x_{m}, x_{n+2}\right) & \leq d\left(x_{m}, x_{m+1}\right)+d\left(x_{m+1}, x_{n+2}\right) \\
& \ll c-\psi(c)+\psi d\left(x_{m}, x_{n+1}\right) \\
& \ll c-\psi(c)+\psi(c)=c .
\end{aligned}
$$

Therefore, (24) holds when $n=n+1$. By induction, we deduce that (24) holds for all $n \geq m$. This is sufficient to conclude that $\left\{x_{n}\right\}$ is a Cauchy sequence. Choose $u \in X$ such that $x_{n} \rightarrow u$. Since $\alpha\left(x_{n}, u\right) \geq 1$ for all $n$ and $F$ is $\alpha^{*}$-admissible, so $\alpha^{*}\left(F x_{n}, F u\right) \geq 1$ for all $n$. From (3), we have

$$
\psi\left(d\left(x_{n}, u\right)\right) \in \alpha^{*}\left(F x_{n}, F u\right) s\left(F x_{n}, F u\right)
$$


for all $n \in \mathbb{N}$. By Lemma 5(3), we have

$$
\psi\left(d\left(x_{n}, u\right)\right) \in \alpha^{*}\left(F x_{n}, F u\right) s\left(x_{n+1}, F u\right) .
$$

By definition, we can take $v_{n} \in F u$ such that

$$
\psi\left(d\left(x_{n}, u\right)\right) \in \alpha^{*}\left(F x_{n}, F u\right) s\left(d\left(x_{n+1}, v_{n}\right)\right) .
$$

By Lemma 5(4), we have

$$
\begin{aligned}
\psi\left(d\left(x_{n}, u\right)\right) & \in \alpha^{*}\left(F x_{n}, F u\right) s\left(d\left(x_{n+1}, v_{n}\right)\right) \\
& \subseteq s\left(\alpha^{*}\left(F x_{n}, F u\right) d\left(x_{n+1}, v_{n}\right)\right) .
\end{aligned}
$$

So

$$
\alpha^{*}\left(F x_{n}, F u\right) d\left(x_{n+1}, v_{n}\right) \preceq \psi\left(d\left(x_{n}, u\right)\right) .
$$

Hence

$$
\begin{aligned}
0 & \prec d\left(x_{n+1}, v_{n}\right) \\
& \preceq \alpha^{*}\left(F x_{n}, F u\right) d\left(x_{n+1}, v_{n}\right) \\
& \preceq \psi\left(d\left(x_{n}, u\right)\right) \\
& \preceq d\left(x_{n}, u\right) .
\end{aligned}
$$

Moreover, for a given $c \in \operatorname{Int} P$, we have

$$
\begin{aligned}
d\left(u, v_{n}\right) & \leq d\left(u, x_{n+1}\right)+d\left(x_{n+1}, v_{n}\right) \\
& \leq d\left(u, x_{n+1}\right)+\alpha^{*}\left(F x_{n}, F u\right) d\left(x_{n+1}, v_{n}\right) \\
& \preceq d\left(u, x_{n+1}\right)+\psi\left(d\left(x_{n}, u\right)\right) \\
& \leq d\left(u, x_{n+1}\right)+d\left(x_{n}, u\right) \\
& \ll \frac{c}{2}+\frac{c}{2}=c, \quad \text { for } n \geq k=k(c) .
\end{aligned}
$$

Hence, according to Lemma 2(i), we have $\lim _{n \rightarrow \infty} v_{n}=u$. Since $F u$ is closed, $u \in F u$.

Theorem 9. Let $(X, d)$ be a complete cone metric space with cone $P, \alpha: X \times X \rightarrow[0,+\infty)$ be a function, and $F: X \rightarrow$ $C B(X)$ be $\alpha^{*}$-admissible. If there exists a constant $k \in[0,1)$ such that

$$
k d(x, y) \in \alpha^{*}(F x, F y) s(F x, F y)
$$

for all $x, y \in X$. Suppose that there exist $x_{0} \in X, x_{1} \in F x_{0}$ such that $\alpha\left(x_{0}, x_{1}\right) \geq 1$. Assume that if $\left\{x_{n}\right\}$ is a sequence in $X$ such that $\alpha\left(x_{n}, x_{n+1}\right) \geq 1$ for all $n$ and $x_{n} \rightarrow u$ as $n \rightarrow+\infty$; then $\alpha\left(x_{n}, u\right) \geq 1$ for all $n$. Then, there exists a point $x^{*}$ in $X$ such that $x^{*} \in F x^{*}$.

Proof. Take $\psi(t)=k t$ in Theorem 8 .

Theorem 10. Let $(X, d)$ be a complete cone metric space with cone $P, \psi \in \Psi$ be a strictly increasing map, and $F: X \rightarrow$ $C B(X)$ be multivalued mapping such that

$$
\psi(d(x, y)) \in s(F x, F y)
$$

for all $x, y \in X$. Then, there exists a point $x^{*}$ in $X$ such that $x^{*} \in F x^{*}$.
Proof. Take $\alpha^{*}(F x, F y)=1$ in the Theorem 8 .

Corollary 11. Let $(X, d)$ be a complete cone metric space with cone $P$ and let $F: X \rightarrow C B(X)$ be a multivalued mapping. If there exists a constant $k \in[0,1)$ such that

$$
k d(x, y) \in s(F x, F y)
$$

for all $x, y \in X$, then, there exists a point $x^{*}$ in $X$ such that $x^{*} \in F x^{*}$.

Proof. Take $\psi(t)=k t$ and $\alpha^{*}(F x, F y)=1$ in the Theorem 8 .

Corollary 12 (see [20]). Let $(X, d)$ be a complete metric space, $\alpha: X \times X \rightarrow[0,+\infty)$ be a function, $\psi \in \Psi$ be a strictly increasing map, and $F: X \rightarrow C B(X)$ be $\alpha^{*}$-admissible such that

$$
\alpha^{*}(F x, F y) H(F x, F y) \leq \psi(d(x, y))
$$

for all $x, y \in X$. Suppose that there exist $x_{0} \in X$ such that $\alpha\left(x_{0}, F x_{0}\right) \geq 1$. Assume that if $\left\{x_{n}\right\}$ is a sequence in $X$ such that $\alpha\left(x_{n}, x_{n+1}\right) \geq 1$ for all $n$ and $x_{n} \rightarrow u$ as $n \rightarrow+\infty$ then $\alpha\left(x_{n}, u\right) \geq 1$ for all $n$. Then, there exists a point $x^{*}$ in $X$ such that $x^{*} \in F x^{*}$.

By Remark 6, we have the following corollaries.

Corollary 13 (see [20]). Let $(X, d)$ be a complete metric space, $\psi \in \Psi$ be a strictly increasing map, and $F: X \rightarrow C B(X)$ be a multivalued mapping such that

$$
H(F x, F y) \leq \psi(d(x, y))
$$

for all $x, y \in X$. Then, there exists a point $x^{*}$ in $X$ such that $x^{*} \in F x^{*}$.

Proof. Take $\alpha^{*}(F x, F y)=1$ in the Corollary 12.

Corollary 14 (see $[20])$. Let $(X, d)$ be a complete metric space, $\alpha: X \times X \rightarrow[0,+\infty)$ be a function, and $F: X \rightarrow C B(X)$ be $\alpha^{*}$-admissible. If there exists a constant $k \in[0,1)$ such that

$$
\alpha^{*}(F x, F y) H(F x, F y) \leq k d(x, y)
$$

for all $x, y \in X$. Suppose that there exist $x_{0} \in X$ such that $\alpha\left(x_{0}, F x_{0}\right) \geq 1$. Assume that if $\left\{x_{n}\right\}$ is a sequence in $X$ such that $\alpha\left(x_{n}, x_{n+1}\right) \geq 1$ for all $n$ and $x_{n} \rightarrow$ us $n \rightarrow+\infty$ then $\alpha\left(x_{n}, u\right) \geq 1$ for all $n$. Then, there exists a point $x^{*}$ in $X$ such that $x^{*} \in F x^{*}$.

Proof. Take $\psi(t)=k t$ in the Corollary 13 .

Corollary 15 (see [25]). Let $(X, d)$ be a complete metric space and let $F: X \rightarrow C B(X)$ be a multivalued mapping. If there exists a constant $k \in[0,1)$ such that

$$
H(F x, F y) \leq k d(x, y)
$$

for all $x, y \in X$. Then, there exists a point $x^{*}$ in $X$ such that $x^{*} \in F x^{*}$. 
Proof. Take $\alpha^{*}(F x, F y)=1$ in the Corollary 14 .

Example 16. Let $X=[0,1], E=C^{1}[0,1], P=\{\theta \preceq x(t): t \in$ $X\}$, where $\theta(t)=0$ for all $t \in X$. Define $d: X \times X \rightarrow E$ by

$$
d(x, y)=|x-y| e^{t}
$$

and $F: X \rightarrow 2^{X}$ by $F x=[0,(x / 12)]$ for all $x \in X$ and

$$
\alpha(x, y)= \begin{cases}\frac{1}{|x-y|} & \text { if } x \neq y \\ 1 & \text { if } x=y .\end{cases}
$$

Then, $\alpha(x, y) \geq 1 \Rightarrow \alpha^{*}(F x, F y)=\inf \{\alpha(x, y): x \in F x, y \in$ $F y\} \geq 1$. Then, clearly $F$ is $\alpha^{*}$-admissible. Now for $x, y$ and $x \leq y$, we get

$$
\begin{aligned}
\psi(d(x, y)) & =\frac{1}{5}|x-y| e^{t} \geq \frac{1}{12}|x-y| e^{t} \\
& =\alpha^{*}(F x, F y) s(F x, F y)
\end{aligned}
$$

which implies that

$$
\psi(d(x, y)) \in \alpha^{*}(F x, F y) s(F x, F y)
$$

So $F$ is $\alpha^{*}-\psi$-contractive multivalued mapping on $X$ where $\psi(t)=t / 5$. Thus, all the conditions of main result are satisfied to obtain the fixed point of $F$.

\section{Conflict of Interests}

The authors declare that they have no competing interests.

\section{Authors' Contributions}

All authors contributed equally and significantly in writing this paper. All authors read and approved the final paper.

\section{Acknowledgments}

The authors thank the editor and the referees for their valuable comments and suggestions which improved greatly the quality of this paper. The first author gratefully acknowledges the support from the Deanship of Scientific Research (DSR) at King Abdulaziz University (KAU) during this research.

\section{References}

[1] L.-G. Huang and X. Zhang, "Cone metric spaces and fixed point theorems of contractive mappings," Journal of Mathematical Analysis and Applications, vol. 332, no. 2, pp. 1468-1476, 2007.

[2] Sh. Rezapour and R. Hamlbarani, "Some notes on the paper 'Cone metric spaces and fixed point theorems of contractive mappings"', Journal of Mathematical Analysis and Applications, vol. 345, pp. 719-724, 2008.

[3] S. Jankovi, Z. Kadelburg, and S. Radenovi, "On cone metric spaces: a survey," Nonlinear Analysis, Theory, Methods \& Applications, vol. 74, no. 7, pp. 2591-2601, 2011.
[4] A. Azam and N. Mehmood, "Multivalued fixed point theorems in tvs-cone metric spaces," Fixed Point Theory and Applications, vol. 2013, article 184, 2013.

[5] S. H. Cho and J. S. Bae, "Fixed point theorems for multivalued maps in cone metric spaces," Fixed Point Theory and Applications, vol. 2011, p. 87, 2011.

[6] N. Mizoguchi and W. Takahashi, "Fixed point theorems for multivalued mappings on complete metric spaces," Journal of Mathematical Analysis and Applications, vol. 141, no. 1, pp. 177188, 1989.

[7] B. Samet, C. Vetro, and P. Vetro, "Fixed point theorem for $\alpha-\psi$ contractive type mappings," Nonlinear Analysis: Theory, Methods \& Applications, vol. 75, pp. 2154-2165, 2012.

[8] E. Karapinar, P. Kumam, and P. Salimi, "On $\alpha-\psi$-Meir-Keeler contractive mappings," Fixed Point Theory and Applications, vol. 2013, p. 94, 2013.

[9] M. Arshad and J. Ahmad, "On multivalued contractions in cone metric spaces without normality," The Scientific World Journal, vol. 2013, Article ID 481601, 3 pages, 2013.

[10] H. Aydi, "A common fixed point result for a $(\psi, \varphi)$-weak contractive condition type," Journal of Applied Mathematics \& Informatics, vol. 30, pp. 809-820, 2012.

[11] A. Azam and M. Arshad, "Fixed points of a sequence of locally contractive multivalued maps," Computers and Mathematics with Applications, vol. 57, no. 1, pp. 96-100, 2009.

[12] I. Beg and A. Azam, "Fixed points of asymptotically regular multivalued mappings," Journal of the Australian Mathematical Society A, vol. 53, no. 3, pp. 313-326, 1992.

[13] C.-M. Chen, "Fixed point theorems for $\psi$-contractive mappings in ordered metric spaces," Journal of Applied Mathematics, vol. 2012, Article ID 756453, 107 pages, 2012.

[14] C.-M. Chen and T.-H. Chang, "Common fixed point theorems for a weaker Meir-Keeler type function in cone metric spaces," Applied Mathematics Letters, vol. 23, no. 11, pp. 1336-1341, 2010.

[15] C. Di Bari and P. Vetro, " $\varphi$-pairs and common fixed points in cone metric spaces," Rendiconti del Circolo Matematico di Palermo, vol. 57, no. 2, pp. 279-285, 2008.

[16] W.-S. Du, "New cone fixed point theorems for nonlinear multivalued maps with their applications," Applied Mathematics Letters, vol. 24, no. 2, pp. 172-178, 2011.

[17] H. Lakzian, H. Aydi, and B. E. Rhoades:, "Fixed points for $(\varphi, \psi, p)$-weakly contractive mappings in metric spaces with $\omega$ distance," Applied Mathematics and Computation, vol. 219, no. 12, pp. 6777-6782, 2013.

[18] E. Karapinar and B. Samet, "Generalized $(\alpha-\psi)$ contractive type mappings and related fixed point theorems with applications," Abstract and Applied Analysis, vol. 2012, Article ID 793486, 17 pages, 2012.

[19] P. Vetro, "Common fixed points in cone metric spaces," Rendiconti del Circolo Matematico di Palermo, vol. 56, no. 3, pp. 464468, 2007.

[20] J. H. Asl, S. Rezapour, and N. Shahzad, "On fixed points of $\alpha-\psi$-contractive multifunctions," Fixed Point Theory and Applications, vol. 2012, p. 212, 2012.

[21] M. U. Ali and T. Kamran, "On $\left(\propto^{*}-\psi\right)$-contractive multi-valued mappings," Fixed Point Theory and Applications, vol. 2013, p. 137, 2013.

[22] B. Mohammadi, S. Rezapour, and N. Shahzad, "Some results on fixed points of $\alpha-\psi$-Ciric generalized multifunctions," Fixed Point Theory and Applications, vol. 2013, p. 24, 2013. 
[23] P. Salimi, A. Latif, and N. Hussain, "Modified $\alpha-\psi$-contractive mappings with applications," Fixed Point Theory and Applications, vol. 2013, article 151, 2013.

[24] C. Di Bari and P. Vetro, "Weakly $\varphi$-pairs and common fixed points in cone metric spaces," Rendiconti del Circolo Matematico di Palermo, vol. 58, no. 1, pp. 125-132, 2009.

[25] S. Banach, "Sur les opérations dans les ensembles abstraits et leur application aux équations intégrales," Fundamenta Mathematicae, vol. 3, pp. 133-181, 1922. 


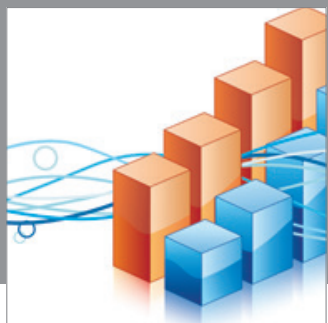

Advances in

Operations Research

mansans

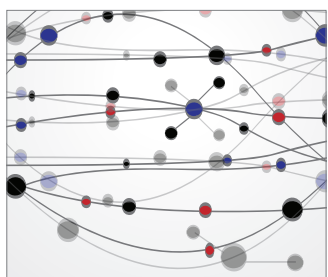

The Scientific World Journal
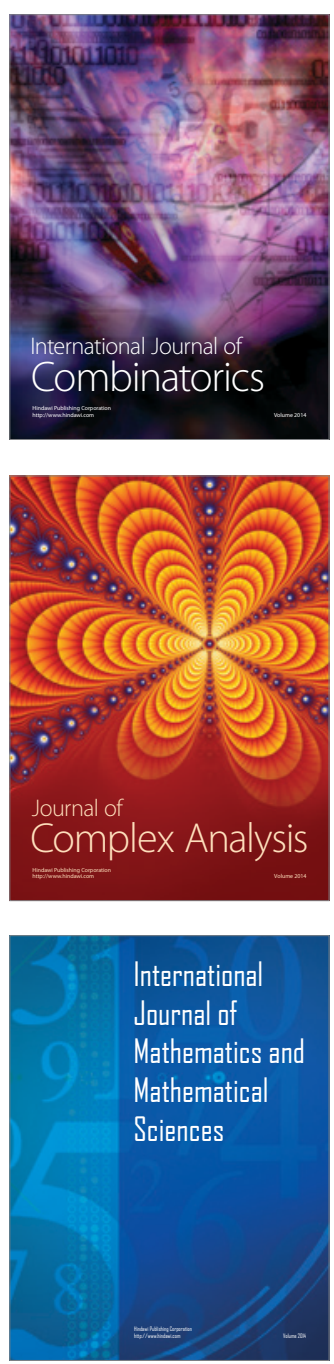
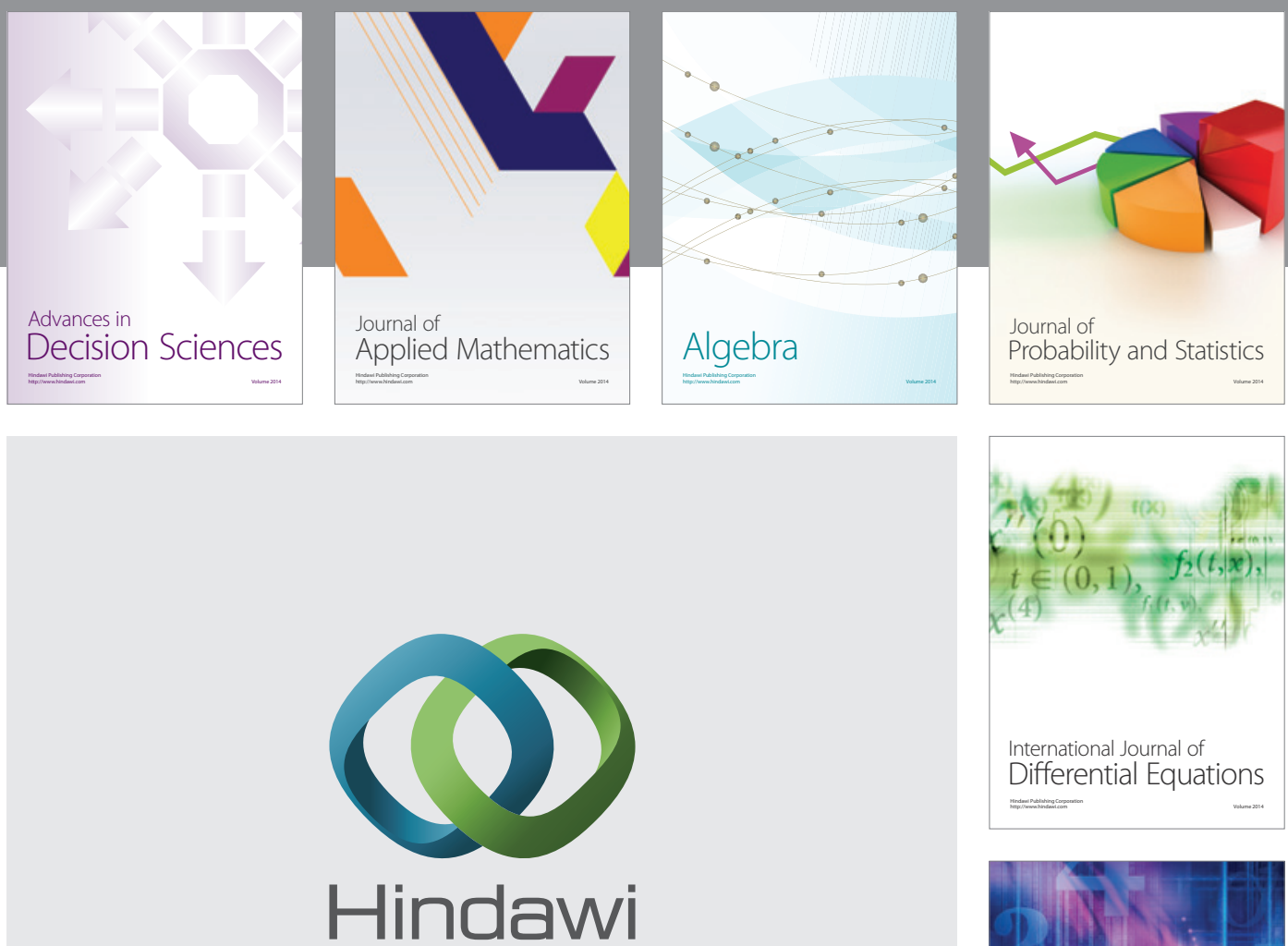

Submit your manuscripts at http://www.hindawi.com
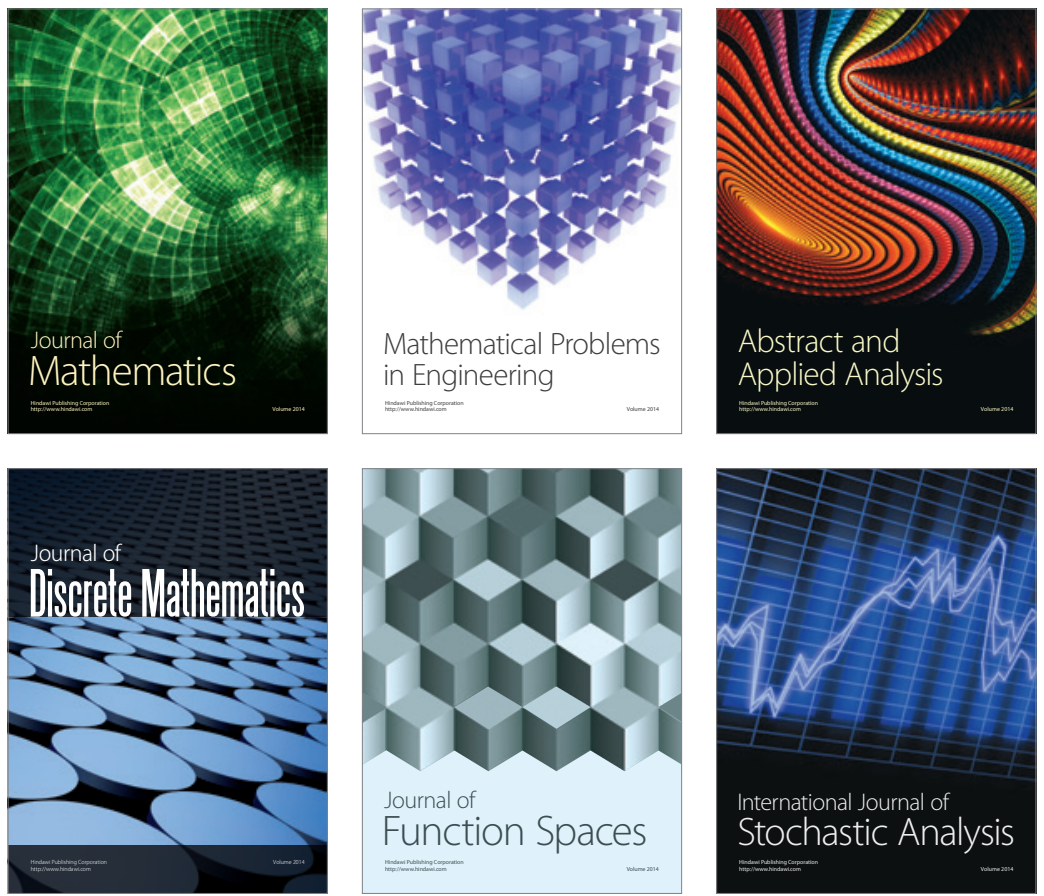

Journal of

Function Spaces

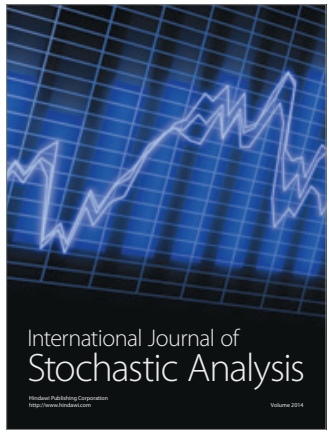

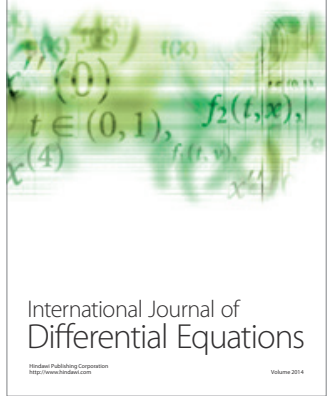
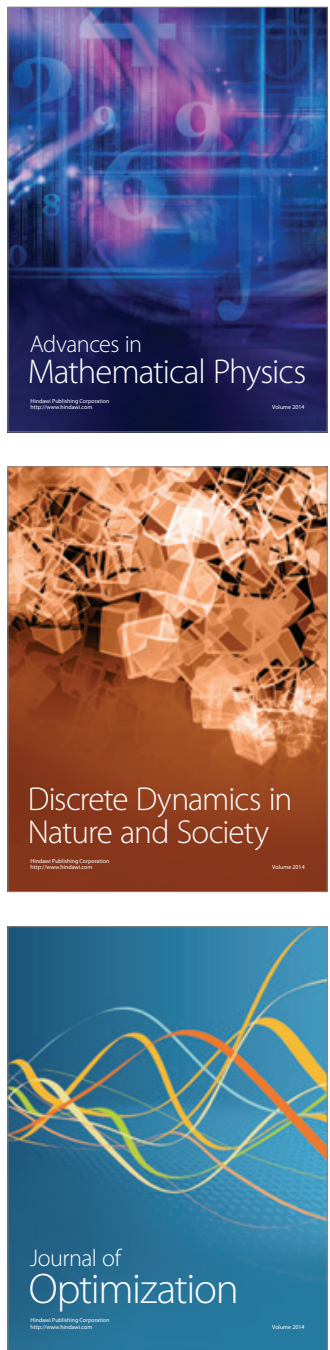